\title{
Fuzzy Logic for Solving an Optimal Control Problem of Hypoxemic Hypoxia Tissue Blood Carbon Dioxide Exchange during Physical Activity
}

\author{
Jean Marie Ntaganda', Mahamat Saleh Daoussa Haggar ${ }^{2 *}$, Benjamin Mampassi ${ }^{3}$ \\ ${ }^{1}$ Department of Applied Mathematics, School of Pure and Applied Sciences, College of Science and Technology, \\ University of Rwanda, Kigali, Rwanda \\ ${ }^{2} N^{\prime}$ Djamena University, N'Djamena, Chad \\ ${ }^{3}$ Cheikh Anta Diop University, Dakar, Senegal \\ Email: jmnta@yahoo.fr, ${ }^{*}$ daoussa haggar@yahoo.fr, mampassi@yahoo.fr
}

Received 7 August 2014; revised 22 September 2014; accepted 7 October 2014

Copyright $(2014$ by authors and Scientific Research Publishing Inc.

This work is licensed under the Creative Commons Attribution International License (CC BY). http://creativecommons.org/licenses/by/4.0/

(c) (;) 0pen Access

\section{Abstract}

This paper aims at using of an approach integrating the fuzzy logic strategy for hypoxemic hypoxia tissue blood carbon dioxide human optimal control problem. To test the efficiency of this strategy, the authors propose a numerical comparison with the direct method by taking the values of determinant parameters of cardiovascular-respiratory system for a 30 years old woman in jogging as her regular physical activity. The results are in good agreement with experimental data.

\section{Keywords}

Fuzzy Logic, Optimal Control, Membership Function, Membership Degree, Hypoxemic-Hypoxia, Pressure, Carbon Dioxide, Oxygen, Numerical Simulation

\section{Introduction}

Hypoxia, or hypoxiation, is a pathological condition related to adequate oxygen supply in human body. The derived adequate oxygen supply can be whole body (generalized hypoxia) or its region (tissue hypoxia). Generalized hypoxia occurs in healthy people when they ascend to high altitude, where it causes altitude sickness leading to potentially fatal complications: high altitude pulmonary edema (HAPE) and high altitude cerebral edema "Corresponding author.

How to cite this paper: Ntaganda, J.M., Daoussa Haggar, M.S. and Mampassi, B. (2014) Fuzzy Logic for Solving an Optimal Control Problem of Hypoxemic Hypoxia Tissue Blood Carbon Dioxide Exchange during Physical Activity. Open Journal of Applied Sciences, 4, 501-514. http://dx.doi.org/10.4236/ojapps.2014.411049 
(HACE) [1]. Hypoxia also occurs in healthy individuals when breathing mixtures of gases with a low oxygen content that is while diving underwater especially when using closed-circuit re-breather systems that control the amount of oxygen in the supplied air. A mild and non-damaging intermittent hypoxia is used intentionally during altitude training to develop an athletic performance adaptation at both the systemic and cellular level.

Hypoxia is also a serious consequence of preterm birth in the neonate. The main cause for this is that the lungs of the human fetus are among the last organs to develop during pregnancy. To assist the lungs to distribute oxygenated blood throughout the body, infants at risk of hypoxia are often placed inside an incubator capable of providing continuous positive airway pressure (also known as a humidicrib).

Hypoxia denotes oxygen deficiency at the mitochondrial sites due to insufficient delivery of oxygen (low $\mathrm{PaO}_{2}$ ) or inability to use oxygen (normal $\mathrm{PaO}_{2}$ ). Hypotonic hypoxia is characterized by a $\mathrm{PaO}_{2}$ less than $7.3 \mathrm{kPa}(55 \mathrm{mmHg})$. Below this threshold, the ventilation starts to increase by carotid body activity. Acute hypoxia with low $\mathrm{PaO}_{2}$ stimulates the carotid bodies. This triggers a rise in ventilation (primary hyperventilation). The hyperventilation reduces $\mathrm{PaO}_{2}$ and $\left[\mathrm{H}^{+}\right]$, which limits the initial rise in ventilation, because it decreases the carotid body and central chemoreceptor stimuli.

In humans, hypoxia is detected by chemoreceptors in the carotid body. This response does not control ventilation rate at normal $\mathrm{PaO}_{2}$, but below normal the activity of neurons innervating these receptors increases dramatically, so much so to override the signals from central chemoreceptors in the hypothalamus, increasing $\mathrm{PaO}_{2}$ despite a falling $\mathrm{PaCO}_{2}$

Any physical activity will obviously cause the body to demand more oxygen for normal functioning. The muscles will rob the brain of the marginal amounts of oxygen available in the blood and the time of onset of hypoxic symptoms is shortened.

This paper is organized as follows. Section 2 presents the model equations and optimal control problem. A short description of strategy approach by fuzzy logic for solving optimal control problems is discussed in this section. Section 3 is interested in the application of the direct approach and the approach integrating the fuzzy logic for solving an optimal control problem of glucose-insulin in diabetic human. The numerical simulation is presented in Section 4. Finally, we present conclusion remarks in Section 5.

\section{Methods}

First of all we focus on the models equations as developed by Guillermo Gutierrez [2]. The diagram for a two compartmental model is illustrated in the Figure 1 where mass transport model of tissue $\mathrm{CO}_{2}$ exchange is developed to examine the relative contributions of blood flow and cellular hypoxia (dysoxia) to increases in tissue and venous blood $\mathrm{CO}_{2}$ concentration.

From the diagram presented in the Figure 1, the equations of the model can be formulated as follows.

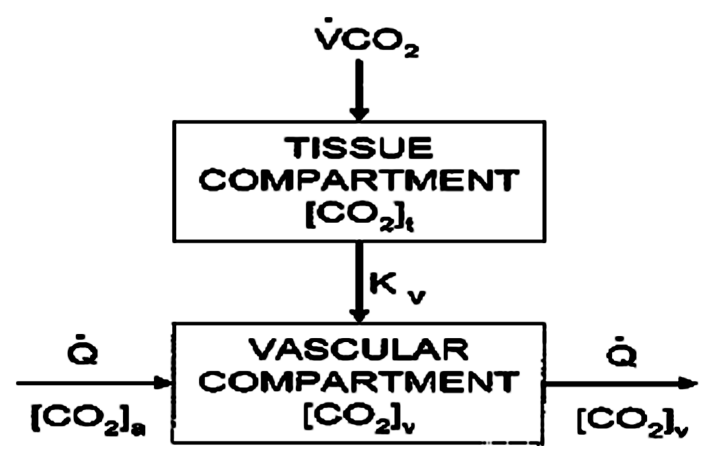

Figure 1. Diagram for the tissue $\mathrm{CO}_{2}$ exchange model where $\left[\mathrm{CO}_{2}\right]$ represents the total $\mathrm{CO}_{2}$ concentration (dissolved and bound) and the subscripts $t$ and $v$ denote the tissue and vascular compartments respectively. $K_{v}$ is the mass transfer coefficient for $\mathrm{CO}_{2}$. For the vascular compartment, the rate of change of $\left[\mathrm{CO}_{2}\right]_{v}$ depends on blood flow per unit volume of tissue $(\dot{Q})$. $\dot{V} \mathrm{CO}_{2}$ denotes $\mathrm{CO}_{2}$ production. 


$$
\begin{gathered}
\frac{\mathrm{d}\left[\mathrm{CO}_{2}\right]_{t}}{\mathrm{~d} t}=\dot{V} \mathrm{CO}_{2}-\mathrm{Kv}\left(\left[\mathrm{CO}_{2}\right]_{t}-\left[\mathrm{CO}_{2}\right]_{v}\right) ; \\
\frac{\mathrm{d}\left[\mathrm{CO}_{2}\right]_{v}}{\mathrm{~d} t}=\dot{Q}\left(\left[\mathrm{CO}_{2}\right]_{a}-\left[\mathrm{CO}_{2}\right]_{v}\right)+K v\left(\left[\mathrm{CO}_{2}\right]_{t}-\left[\mathrm{CO}_{2}\right]_{v}\right),
\end{gathered}
$$

where the variable states $\left[\mathrm{CO}_{2}\right]_{t}$ and $\left[\mathrm{CO}_{2}\right]_{v}$ are function of time we prefer to denote also $\mathrm{t}$.

It is known that the human respiratory control system varies the ventilation rate $\dot{V}_{A}$ in response to the levels of $\mathrm{CO}_{2}$ and $\mathrm{O}_{2}$ in the body and the control mechanisms of cardiovascular system influences global control in the blood vessels as well as heart rate $H$ for changing blood flow $\dot{Q}$ [3]. Generally, during physical activity in altitude and particular in the hypoxia case, the control mechanism of these two system plays a crucial role.

Consequently, the control of cardiovascular and respiratory system is described via the following two ordinary differential equations respectively.

$$
\begin{aligned}
\frac{\mathrm{d} H}{\mathrm{~d} t} & =u(t) ; \\
\frac{\mathrm{d} \dot{V}_{A}}{\mathrm{~d} t} & =v(t),
\end{aligned}
$$

where the functions $u(t)$ and $v(t)$ are determined by an optimality criterion.

Now let be interested in writing the arterial blood $\mathrm{PaO}_{2}$ and $\mathrm{PaCO}_{2}$. First of all the venous concentration of $\mathrm{O}_{2}$ in the vascular compartment is calculated from Fick's equation that allows to determine the rate at which oxygen is being used during physical activity as

$$
\left[\mathrm{O}_{2}\right]_{v}=\left[\mathrm{O}_{2}\right]_{a}-\frac{\dot{V} \mathrm{O}_{2}}{\dot{Q}},
$$

where $\left[\mathrm{O}_{2}\right]_{a}$ is arterial concentration of $\mathrm{O}_{2}$ and $\dot{\mathrm{V}} \mathrm{O}_{2}$ denotes the production of $\mathrm{O}_{2}$ Therefore the venous oxyhemoglobin saturation $\left(\mathrm{SvO}_{2}\right)$ is calculated from $\left[\mathrm{O}_{2}\right]_{v}$ by neglecting the contribution of dissolved $\mathrm{O}_{2}$ as follows

$$
\left(\mathrm{SvO}_{2}\right)=\frac{\left[\mathrm{O}_{2}\right]_{v}}{1.34 \times[\mathrm{Hb}]},
$$

where $[H b]$ is the blood hemoglobin concentration in $\mathrm{g} / \mathrm{L}$

By considering the calculation done in [2], the arterial pressure of $\mathrm{O}_{2} \quad[4]$ is

$$
\mathrm{PaO}_{2}=A \times \exp [2.016(7.4-\mathrm{pH})],
$$

where $\mathrm{pH}$ is taken as constant 7.40 and

$$
A=\exp \left[0.385 \times \ln \left(\frac{\mathrm{SvO}_{2}}{1-\mathrm{SvO}_{2}}\right)+3.321-\left(72 \times \mathrm{SvO}_{2}\right)-\frac{\left[\mathrm{SvO}_{2}\right]^{6}}{6}\right] .
$$

Similarly, blood $\mathrm{PaCO}_{2}$ is calculated on the basis of the Henderson-Hasselbach equation [5]

$$
\mathrm{PaCO}_{2}=\frac{B}{0.06868 \times\left[10^{(1.04214 \mathrm{pH}-6.41036)}\right]},
$$

where $B$ is $\mathrm{CO}_{2}$ content of plasma defined by Douglas [6] as follows

$$
B=\frac{\left[\mathrm{CO}_{2}\right]_{v} \times\left(\left(2.244-0.422 \times \mathrm{SO}_{2}\right) \times(8.74-\mathrm{pH})\right)}{\left(\left(2.244-0.422 \times \mathrm{SO}_{2}\right) \times(8.74-\mathrm{pH})\right)-0.43},
$$

The respiratory control system aims at keeping $\mathrm{PaO}_{2}$ and $\mathrm{PaCO}_{2}$ closely to their equilibrium values $\mathrm{P}^{f} \mathrm{aO}_{2}$ and $\mathrm{P}^{f} \mathrm{aCO}_{2}$ respectively. Furthermore, the cost functional can be formulated in the following way. 
Find $u^{*}(t)$ and $v^{*}(t)$ solution of

$$
J(u, v)=\int_{0}^{T_{\max }} q_{\mathrm{CO}_{2}}\left(\mathrm{PaCO}_{2}-\mathrm{P}^{f} \mathrm{aCO}_{2}\right)^{2}+q_{\mathrm{O}_{2}}\left(\mathrm{PaO}_{2}-\mathrm{P}^{f} \mathrm{aO}_{2}\right)^{2}+q_{u} u(t)^{2}+q_{v} v(t)^{2}
$$

subject to the system (1)-(2) and (3)-(4).

In the relation (7), the positive scalar coefficients $q_{\mathrm{CO}_{2}}, q_{\mathrm{O}_{2}}, q_{u}$ and $q_{v}$ determine how much weight is attached to each cost component term in the integrand while $T_{\max }$ denotes the maximum time that the physical activity can take.

Let us consider $V^{N}$ the vector space that is span of a base of linear $B$-splines functions

$$
\mathbf{B}^{N}=\left\{\psi_{j}^{N}, j=1, \cdots, N\right\}
$$

on a regular grid

$$
\Omega_{N}=\left\{t_{k}=\frac{k T_{\max }}{N}, k=0, \cdots, N\right\} .
$$

The functions $\psi_{j}^{N}, \quad j=1, \cdots, N$ verify the following relation

$$
\psi_{j}^{N}\left(t_{k}\right)=\delta_{i k}
$$

where $\delta$ denotes Kronecker symbol. The discretisation of the optimal problem (7) is done by setting the state vector

$$
x=\left(\mathrm{PaCO}_{2}, \mathrm{PaO}_{2}\right)^{\mathrm{T}}
$$

and the desired final vector

$$
x^{f}=\left(\mathrm{P}^{f} \mathrm{aCO}_{2}, \mathrm{P}^{f} \mathrm{aO}_{2}\right)^{\mathrm{T}}
$$

such that it can be written as follows.

$$
\min _{\lambda \in Q} J^{N}(\lambda)=\int_{0}^{T_{\max }}\left(\sum_{i=1}^{2} k_{i} \cdot\left(x_{i}^{N}(t)-x_{i}^{f}\right)^{2}+\sum_{j=1}^{2} q_{j} \cdot\left(\lambda_{j}(t)\right)^{2}\right) \mathrm{d} t ;
$$

where

$$
\lambda=(u, v)^{\mathrm{T}}, \quad k=\left(q_{\mathrm{CO}_{2}}, q_{\mathrm{O}_{2}}\right)^{\mathrm{T}} \text { and } q=\left(q_{u}, q_{v}\right)^{\mathrm{T}}
$$

with $x_{i}, x_{i}^{f}, \lambda_{i}, k_{i}$ and $q_{i}$ respectively the $i^{\text {th }}$ component of the vectors $x, x^{f}, \lambda, k$ and $q$.

We are looking for $\lambda^{M}=\left(\lambda_{1}^{M}, \lambda_{2}^{M}\right) \in Q^{M}$ an approximated solution of (10) in the set $Q^{M}=\left(V^{M}\right)^{2}$ such that

$$
\lambda_{j}^{M}=\sum_{k=0}^{M} \lambda_{j, k}^{M} \psi_{k}(t), j=1,2
$$

Therefore the cost function (10) becomes

$$
J^{N}\left(\lambda^{M}\right) \approx \sum_{k=1}^{M}\left(\sum_{i=1}^{2} k_{i}\left(x_{i}^{N}\left(t_{k}\right)-x_{i}^{f}\right)^{2}+\sum_{j=1}^{2} q_{j}\left(\lambda_{j, k}^{M}\right)^{2}\right) h, \quad \text { with } h=\frac{T_{\max }}{N}
$$

where (12) is determined using rectangular method such that the discretisation is done on a regular grid $\Omega_{M}$.

Finally, the discrete formulation of optimal problem (7) subject to (1)-(2) and (3)-(4) is written as follows.

$$
\min _{\lambda^{M} \in R^{(M+1)} \times R^{(M+1)}} J^{N}\left(\underline{\lambda}^{M}\right) \approx h\left(\left(Y^{\mathrm{T}} R Y\right)+\left(\underline{\lambda}^{M}\right)^{\mathrm{T}} B \underline{\lambda}^{M}\right) ;
$$

where $\underline{\lambda}^{M}$ is a matrix $(M+1) \times 2$ such that $\lambda_{j, k}^{M}$ are components of the function $\lambda_{j}^{N}$ in the set $\mathbf{B}^{N}$ and $Y$ 
represents the matrix with $(i, k)^{t h}$ component is $x_{i}^{N}\left(t_{k}\right)-x_{i}^{f}$ where $x^{N}=\left(x_{1}^{N}, x_{2}^{N}\right)^{\mathrm{T}}$ denotes the two first components of solution of the system (1)-(2) and (3)-(4) associated to $\lambda=\lambda^{N}, R$ and $B$ are matrix defined by

$$
R=\left(\begin{array}{cc}
k_{1} & 0 \\
0 & k_{2}
\end{array}\right), \quad B=\left(\begin{array}{cc}
q_{1} & 0 \\
0 & q_{2}
\end{array}\right)
$$

\section{Description of Fuzzy Logic Strategy Approach}

Let us consider the following problem.

Find $U_{k} \in R^{N}, k=0, \cdots, N-1$ that minimizes

$$
J\left(U_{0}, \cdots, U_{N-1}\right)=\sum_{k=0}^{N-1}\left(x_{k}^{\mathrm{T}} R x_{k}+U_{k}^{\mathrm{T}} Q U_{k}\right)
$$

subject to

$$
\left\{\begin{array}{l}
x_{k+1}=f_{k}\left(x_{k}, U_{k}\right), \\
x_{k} \in R^{n}, U_{k} \in R^{m},
\end{array} \quad k=0, \cdots, N-1\right.
$$

where $R$ and $Q$ are positive defined matrices.

The problems (15) and (16) can be solved by the dynamic programming method. This method has a fast convergence, its convergence rate is quadratic and the optimal solution is often represented as a state of control feedback [7]. However, the solution determined by this method depends on the choice of the initial trajectory and in some cases this solution is not optimal. It is for this reason that the integration of the fuzzy logic [8] can permit to determine quickly the optimal solution. We develop a linearization strategy of the subject system by an approach based on the fuzzy logic. This approach had been developed by Takagi-Sugeno [9] [10]. The model that has been introduced in 1985 by Takagi-Sugeno permits to get some fuzzy linearization regions in the state space [11]. While taking these fuzzy regions as basis, non linear system is decomposed in a structure multi models which is composed of several independent linear models [12]. The linearization is made around an operating point contained in these regions.

Let's consider the set of operating point $X_{i} \quad i=1, \cdots, S$. Different fuzzy approximations of the nonlinear term $N L(x)$ can be considered.

The approximation of order zero gives:

$$
N L(x) \approx N L_{0}(x)=N L\left(x_{i}\right)
$$

Using the first order of Taylor expansion series we obtain:

$$
N L(x) \approx N L_{1}(x)=N L\left(x_{i}\right)+\left(\frac{\mathrm{d} N L(x)}{\mathrm{d} x}\right)_{x_{i}}^{\mathrm{T}}\left(x-x_{i}\right) .
$$

To improve this approximation, we introduce the factor of the consequence for fuzzy Takagi-Sugeno system. This factor permits to minimize the error between the non linear function and the fuzzy approximation. If $\varepsilon$ designates this factor, the approximation (18) can be formulated as the following form:

$$
\begin{aligned}
N L(x) & \approx(1-\beta) N L_{0}(x)+\varepsilon N L_{1}(x) \\
& \approx N L\left(x_{i}\right)+\beta\left(\frac{\mathrm{d} N L(X)}{\mathrm{d} x}\right)_{x_{i}}^{T}\left(x-x_{i}\right), \quad \text { with } \quad 0 \leq \beta \leq 1 .
\end{aligned}
$$

If one replaces the term $N L$ by its value approached in (16), the linearization around $x_{i}$ leads to

$$
x_{k+1}=A_{i, k} X_{k}+B_{i, k} U_{k}+C_{i, k}, \quad i=1, \cdots, S ; \quad k=0, \cdots, N-1
$$

where $A_{i, k}$ and $B_{i, k}$ are square matrix which has $N \times N$ order and $C_{i, k}$ matrix with $N \times 1$ order.

Therefore, the optimal control problems (15) and (16) become a linear quadratic problem which the feedback control is given by the following expression [13] [14]: 


$$
U_{i, k}=-K_{i} X_{k}, \quad i=1, \cdots, S ; \quad k=0, \cdots, N-1 .
$$

where

$$
K_{i}=\left(Q+B_{i}^{\mathrm{T}} E_{i} B_{i}\right)^{-1} B_{i}^{\mathrm{T}} E_{i} A_{i}
$$

is the feedback gain matrix and $E_{i}$ discreet Riccati equation solution of the following form

$$
E_{i}-Q-A_{i}^{\mathrm{T}} E_{i} A_{i}+A_{i}^{\mathrm{T}} E_{i} B_{i}\left(R+B_{i}^{\mathrm{T}} E_{i} B_{i}\right)^{-1} B_{i}^{\mathrm{T}} E_{i} A_{i}=0
$$

It is obvious that the linearization around every operating point gives the system for which the equations have the form (20). Because there are $S$ operating points, we have $S$ systems which have this form. Therefore, according to the relation (21) $S$ controls are determined. The defuzzyfication method [10] permits to determine only one system and only one control $U_{k}$.

Then, this transformation gives the following equation:

$$
\begin{gathered}
x_{k+1}=A x_{k}+B U_{k}+C, \quad k=0, \cdots, N-1 ; \\
U_{k}=-K x_{k}, \quad k=0, \cdots, N,
\end{gathered}
$$

where

$$
A=\frac{\sum_{i=1}^{S} \omega_{i}\left(x_{i}\right) A_{i, k}}{\sum_{i=1}^{S} \omega_{i}\left(x_{i}\right)}, \quad B=\frac{\sum_{i=1}^{S} \omega_{i}\left(x_{i}\right) B_{i, k}}{\sum_{i=1}^{S} \omega_{i}\left(x_{i}\right)} \quad C=\frac{\sum_{i=1}^{S} \omega_{i}\left(x_{i}\right) C_{i, k}}{\sum_{i=1}^{S} \omega_{i}\left(x_{i}\right)}, \quad \text { and } \quad K=\frac{\sum_{i=1}^{S} \omega_{i}\left(x_{i}\right) K_{i, k}}{\sum_{i=1}^{S} \omega_{i}\left(x_{i}\right)}
$$

and where $\omega_{i}\left(x_{i}\right)$ designates membership degree partner to the operating point $x_{i}$.

\section{Numerical Approaches for Solving the Optimal Control Problem (7), (1)-(4)}

\subsection{Fuzzy Strategy}

To approximate the optimal control problems (7), (1)-(2) and (3)-(4), we propose to use the explicit Euler scheme. The stability of this scheme constitutes an advantage to approach some ordinary differential equations.

The discretisation of the constraints (1)-(2) and (3)-(4) is done using the first order explicit Euler method. From the Equations (1)-(2) and (3)-(4) and taking $\alpha=R Q \times S V \times\left(\left[\mathrm{O}_{2}\right]_{a}-\left[\mathrm{O}_{2}\right]_{V}\right)$ and $\beta=\dot{Q} \times K_{\mathrm{CO}_{2}} \times \dot{V} \mathrm{CO}_{2} \mathrm{~K}$ we have the following system

$$
\left\{\begin{array}{l}
\frac{\mathrm{d}\left[\mathrm{CO}_{2}\right]_{t}}{\mathrm{~d} t}=\alpha H-K v\left(\left[\mathrm{CO}_{2}\right]_{t}-\left[\mathrm{CO}_{2}\right]_{v}\right) \\
\frac{\mathrm{d}\left[\mathrm{CO}_{2}\right]_{v}}{\mathrm{~d} t}=K v\left[\mathrm{CO}_{2}\right]_{t}+\frac{\beta}{\dot{V}_{A}}-(\dot{Q}+K v)\left[\mathrm{CO}_{2}\right]_{v}+\dot{Q} k_{\mathrm{CO}_{2}} \\
\frac{\mathrm{d} H}{\mathrm{~d} t}=u(t) \\
\frac{\mathrm{d} \dot{V}_{\mathrm{A}}}{\mathrm{d} t}=v(t)
\end{array}\right.
$$

Applying the first order explicit Euler's method, the system (27) is transformed as follow

$$
\left\{\begin{array}{l}
{\left[\mathrm{CO}_{2}\right]_{t}^{k+1}=\left[\mathrm{CO}_{2}\right]_{t}^{k}+h\left(-K v\left[\mathrm{CO}_{2}\right]_{t}^{k}+K v\left[\mathrm{CO}_{2}\right]_{v}^{k}+\alpha H^{k}\right)} \\
{\left[\mathrm{CO}_{2}\right]_{v}^{k+1}=\left[\mathrm{CO}_{2}\right]_{v}^{k}+h\left(K v\left[\mathrm{CO}_{2}\right]_{t}^{k}-(\dot{Q}+K v)\left[\mathrm{CO}_{2}\right]_{v}^{k}+\frac{\beta}{\dot{V}_{A}^{k}}+\dot{Q} k_{\mathrm{CO}_{2}}\right)} \\
H^{k+1}=H^{k}+h(u(t)) \\
\dot{V}_{A}^{k+1}=\dot{V}_{A}^{k}+h(v(t)) .
\end{array}\right.
$$


where $h=\frac{T_{\max }}{N}$. Taking $X=\left(\left[\mathrm{CO}_{2}\right]_{t},\left[\mathrm{CO}_{2}\right]_{v}, H, \dot{V}_{A}\right)^{\mathrm{T}}$ as operating point and assuming $s=1,2,3$ as operating point number related to each operating point we have the system

$$
X_{s}^{k+1}=A_{s} X_{k, s}+B_{s} U_{k, s}+C_{s}, \quad s=1,2,3,
$$

where

$$
A_{s}=\left(\begin{array}{cccc}
1-h K v & h K v & \alpha h & 0 \\
h K v & 1-h(\dot{Q}+K v) & 0 & 0 \\
0 & 0 & h & 0 \\
0 & 0 & 0 & h
\end{array}\right) \quad B_{s}=h\left(\begin{array}{cccc}
0 & 0 & 0 & 0 \\
0 & 0 & 0 & 0 \\
1 & 0 & 0 & 0 \\
0 & 1 & 0 & 0
\end{array}\right) \text { and } C_{s}=h\left(\begin{array}{c}
0 \\
\dot{Q} k_{\mathrm{CO}_{2}}+\frac{\beta}{\dot{V}_{A, s}^{k}} \\
0 \\
0
\end{array}\right)
$$

Let us set the following variable change

$$
Y=\left(\mathrm{PaCO}_{2}-\mathrm{P}^{f} \mathrm{aCO}_{2}, \mathrm{PaO}_{2}-\mathrm{P}^{f} \mathrm{aO}_{2}\right)^{\mathrm{T}}
$$

that is

$$
Y=x-x^{f}
$$

The system (27) can be formulated using the relations (6) and (30) but here we prefer to keep this form. The use of these relations is taken into account in numerical simulation. Therefore, the approximation of objective function (7) is made using the rectangular method and it becomes

$$
J(Y, U)=\sum_{k=0}^{N-1}\left(Y_{k}^{\mathrm{T}} R Y_{k}+U_{k}^{\mathrm{T}} B U_{k}\right) h,
$$

where

$$
U=(u, v)^{\mathrm{T}}
$$

and where $R, B$ and $h$ are the same as taken in subsection 2.1. Finally, the optimal control problems (7), (1)-(2) and (3)-(4) becomes the following a linear quadratic (LQ) problem.

Find $U^{*}=\left(U_{0}^{*}, \cdots, U_{N-1}^{*}\right)^{\mathrm{T}}$ solution of

$$
\min _{U} J(Y, U)=\sum_{k=0}^{N-1}\left(Y_{k}^{\mathrm{T}} R Y_{k}+U_{k}^{\mathrm{T}} B U_{k}\right) h
$$

subject to

$$
X_{s}^{k+1}=A_{s} X_{k, s}+B_{s} U_{k, s}+C_{s}, \quad s=1,2,3
$$

\subsection{Direct Approach}

To approximate the system (1)-(4), let us consider

$$
\mathbf{B}^{N}=\left\{\psi_{j}^{N}, j=1, \cdots, N\right\}
$$

a linear $B$-splines basis functions on the uniform grid

$$
\Omega_{N}=\left\{t_{k}=\frac{k T_{\max }}{N}, k=0, \cdots, N\right\}
$$

such that

$$
\psi_{i}^{N}\left(t_{k}\right)=\delta_{i k}
$$

Let us introduce the vector space $W^{N}$ whose the basis is $\mathbf{B}^{N}$. We have 


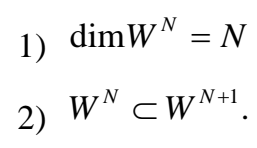

Let us consider $W=C^{0}(0, T)$ and let us take the interpolation operator

$$
\begin{aligned}
& \Pi^{N}: W \rightarrow W^{N} \\
& \varphi \mapsto \Pi^{N} \varphi
\end{aligned}
$$

satisfying

$$
\Pi^{N} \phi\left(t_{k}\right)=\phi\left(t_{k}\right), \quad k=1, \cdots, N
$$

We verify easily that

$$
\begin{aligned}
& \left\|\Pi^{N} \phi-\phi\right\|_{E} \underset{N \rightarrow \infty}{\rightarrow} 0 \quad \forall \phi \in E \\
& \|\| \Pi^{N} \| \mid=\sup _{\substack{\phi \neq 0 \\
\phi \in W}} \frac{\left\|\Pi^{N} \phi\right\|_{E}}{\|\phi\|_{E}}=1 .
\end{aligned}
$$

Therefore, the system (1)-(4) can be approached by the following form Find $\left(\left[\mathrm{CO}_{2}\right]_{t}^{N},\left[\mathrm{CO}_{2}\right]_{v}^{N}, H^{N}, \dot{V}_{A}^{N}\right) \in\left(W^{N}\right)^{2}$ solution of the system

$$
\begin{gathered}
\frac{\mathrm{d}\left[\mathrm{CO}_{2}\right]_{t}^{N}}{\mathrm{~d} t}=\dot{V} \mathrm{CO}_{2}-K v\left(\left[\mathrm{CO}_{2}\right]_{t}^{N}-\left[\mathrm{CO}_{2}\right]_{v}^{N}\right) ; \\
\frac{\mathrm{d}\left[\mathrm{CO}_{2}\right]_{v}^{N}}{\mathrm{~d} t}=\dot{Q}\left(\left[\mathrm{CO}_{2}\right]_{a}-\left[\mathrm{CO}_{2}\right]_{v}^{N}\right)+K v\left(\left[\mathrm{CO}_{2}\right]_{t}^{N}-\left[\mathrm{CO}_{2}\right]_{v}^{N}\right) ; \\
\frac{\mathrm{d} H^{N}}{\mathrm{~d} t}=u^{N}(t) ; \\
\frac{\mathrm{d} \dot{V}_{A}^{N}}{\mathrm{~d} t}=v^{N}(t) ; \\
{\left[\mathrm{CO}_{2}\right]_{t}^{N}(0)=\left[\mathrm{CO}_{2}\right]_{t}^{N, 0}, \quad\left[\mathrm{CO}_{2}\right]_{v}^{N}(0)=\left[\mathrm{CO}_{2}\right]_{v}^{N, 0} ;}
\end{gathered}
$$

such that

$$
\begin{gathered}
\left|\left[\mathrm{CO}_{2}\right]_{t, 0}-\left[\mathrm{CO}_{2}\right]_{t}^{N, 0}\right|_{N \rightarrow \infty}^{\rightarrow} 0 ; \\
\left|\left[\mathrm{CO}_{2}\right]_{v, 0}-\left[\mathrm{CO}_{2}\right]_{V}^{N .0}\right|_{N \rightarrow \infty}^{\rightarrow} 0 ; \\
\left|H_{0}-H^{N, 0}\right|_{N \rightarrow \infty}^{\rightarrow} 0 ; \\
\left|\dot{V}_{A, 0}-\dot{V}_{A}^{N, 0}\right|_{N \rightarrow \infty}^{\rightarrow} 0 .
\end{gathered}
$$

To approximate the optimal problems (1)-(4), let us set $y=\left(\left[\mathrm{CO}_{2}\right]_{t},\left[\mathrm{CO}_{2}\right]_{V}, H, \dot{V}_{A}\right)^{\mathrm{T}}$ the state vector, $y^{0}=\left(\left[\mathrm{CO}_{2}\right]_{t, 0},\left[\mathrm{CO}_{2}\right]_{v, 0}, H, \dot{V}_{A}\right)^{\mathrm{T}}$ the initial state vector, $y^{e}=\left(\left[\mathrm{CO}_{2}\right]_{t}^{e},\left[\mathrm{CO}_{2}\right]_{v}^{e}, H^{e}, \dot{V}_{A}^{e}\right)^{\mathrm{T}}$ the equilibrium state vector $y^{f}=\left(\mathrm{P}^{f} \mathrm{aCO}_{2}, \mathrm{P}^{f} \mathrm{aO}_{2}\right)^{\mathrm{T}}$ the wanted equilibrium vector, $\lambda=(u, v)^{\mathrm{T}}$ the control vector; $y_{i}, y_{i}^{0}$, $y_{i}^{f}$, designate the $i^{\text {th }}$ components of the vector $y, y^{0}, y^{f}$ and $\lambda_{j}$ and $\lambda_{j}^{f}$ denote $j^{\text {th }}$ components of the vector $\lambda$ and $\lambda^{f}$.

Therefore, the problems (1) and (2) can take the following compact form 


$$
\min _{\lambda \in Q} J^{N}(\lambda)=\int_{0}^{T_{\max }}\left(\sum_{i=1}^{2} a_{i} \cdot\left(x_{i}^{N}(t)-x_{i}^{f}\right)^{2}+\sum_{j=1}^{2} b_{j} \cdot\left(\lambda_{j}(t)-\lambda_{j}^{f}\right)^{2}\right) \mathrm{d} t,
$$

where $y^{N}=\left(y_{1}^{N}, y_{2}^{N}\right)^{\mathrm{T}}$ is solution of the approximated solutions (37)-(41).

We must determine $\lambda^{M}=\left(\lambda_{1}^{M}, \lambda_{2}^{M}\right) \in Q^{M}$ an approximate solution of (46) in $Q^{M}=\left(W^{M}\right)^{2}$. It is necessary to note that we can write

$$
\lambda_{j}^{M}=\sum_{k=0}^{M} \lambda_{j, k}^{M} \psi_{k}(t), j=1,2
$$

Therefore, we can approximate the objective function by

$$
J^{N}\left(\lambda^{M}\right) \approx \sum_{k=1}^{M}\left(\sum_{i=1}^{2} a_{i}\left(x_{i}^{N}\left(t_{k}\right)-x_{i}^{f}\right)^{2}+\sum_{j=1}^{2} b_{j}\left(\lambda_{j, k}^{M}\right)^{2}\right) \Delta t
$$

where $\Delta t=\frac{T_{\max }}{N}$. The convergence of the discreet objective function (48) toward the continuous objective function given by the problem (46) has been shown in [15].

Finally, the optimal control problems (7), (1)-(2) and (3)-(4) are minimisation problems with constraint. The discreet formulation of such problem can be written as follows.

Find $\lambda^{*, M} \in R^{(M+1)} \times R^{(M+1)}$ solution of

$$
\min _{\lambda^{M} \in R^{(M+1)} \times R^{(M+1)}} J^{N}\left(\underline{\lambda}^{M}\right) \approx \Delta t\left(\left(Y^{\mathrm{T}} R Y\right)+\left(\underline{\lambda}^{M}\right)^{\mathrm{T}} B \underline{\lambda}^{M}\right)
$$

subject to

$$
\left\{\begin{array}{l}
\frac{\mathrm{d}\left[\mathrm{CO}_{2}\right]_{t}^{N}}{\mathrm{~d} t}=\dot{V} \mathrm{CO}_{2}-K v\left(\left[\mathrm{CO}_{2}\right]_{t}^{N}-\left[\mathrm{CO}_{2}\right]_{v}^{N}\right) \\
\frac{\mathrm{d}\left[\mathrm{CO}_{2}\right]_{v}^{N}}{\mathrm{~d} t}=\dot{Q}\left(\left[\mathrm{CO}_{2}\right]_{a}-\left[\mathrm{CO}_{2}\right]_{v}^{N}\right)+K v\left(\left[\mathrm{CO}_{2}\right]_{t}^{N}-\left[\mathrm{CO}_{2}\right]_{v}^{N}\right) \\
\frac{\mathrm{d} H^{N}}{\mathrm{~d} t}=u^{N}(t) \\
\frac{\mathrm{d} \dot{V}_{A}^{N}}{\mathrm{~d} t}=v^{N}(t),
\end{array}\right.
$$

where $\underline{\lambda}^{M}$ is a matrix $(M+1) \times 2$ such that the components $\lambda_{j, k}^{M}$ are those function $\lambda_{j}^{N}$ in $\mathbf{B}^{N}$ and $Y$ is the matrix such that the $(i, k)^{t h}$ component is $x_{i}^{N}\left(t_{k}\right)-x_{i}^{f}$ where $y^{N}=\left(y_{1}^{N}, y_{2}^{N}\right)^{\mathrm{T}}$ is the solution of (50) associated to $\lambda=\lambda^{N}$.

\section{Numerical Simulation}

Let us consider a hypoxic patient (a 30 year old woman) practicing jogging as physical activity for a period of $T_{\max }=10$ minutes. The values of determinant parameters of a 30 years old woman in this physical activity are given in [15]. Setting up $N=100$ we have $h=0.1$. We consider a universe of discourse $X$ which has four linguistic variables: tissue total $\mathrm{CO}_{2}$ concentration $\left[\mathrm{CO}_{2}\right]_{t}$, vascular total $\mathrm{CO}_{2}$ concentration $\left[\mathrm{CO}_{2}\right]_{v}$, heart rate $(H)$ and ventilation rate $\left(V_{A}\right)$. According to the physiology of cardiovascular-respiratory system, we consider $\left[\mathrm{CO}_{2}\right]_{t} \in[25,35], \quad\left[\mathrm{CO}_{2}\right]_{v} \in[15,30], H \in[50,180]$ and $\dot{V}_{A} \in[4,25]$. Then we take $\mathrm{CO}_{2}$ min (minimum tissue total $\mathrm{CO}_{2}$ concentration), $\mathrm{CO}_{2}$ tmiddle (middle tissue total $\mathrm{CO}_{2}$ concentration) and $\left[\mathrm{CO}_{2}\right]_{t} \max$ (maximum tissue total $\mathrm{CO}_{2}$ concentration) of the linguistic variable $\left[\mathrm{CO}_{2}\right]_{t}$. In an analogous way, $\left[\mathrm{CO}_{2}\right]_{V}$ min, $\left[\mathrm{CO}_{2}\right]_{V}$ middle and $\left[\mathrm{CO}_{2}\right]_{V} \max$ (respectively Hmin, Hmiddle and Hmax; $V_{A} \min$, $V_{A}$ middle and $V_{A}$ max) are the terms of the variable linguistic $\left[\mathrm{CO}_{2}\right]_{V}$ (respectively $H$ and $V_{A}$ ). During the 
physical activity, tissue total $\mathrm{CO}_{2}$ concentration (respectively vascular total $\mathrm{CO}_{2}$ concentration, heart rate and ventilation rate) vary such that we can consider a universe of discourse $X$ where the labels are centered at 25, 30 and 35 (respectively 15, 22.5 and 30; 50, 115 and 180 and 4, 14.5 and 25). It is obvious that these points take the corresponding values in the labels centers of a universe of discourse $X$ [8].

The operating points associated to those linguistic variables are given in the Table 1, membership functions associated to this labeling are represented in the Figure 2 and Figure 3 and Table 2 shows the obtained degrees of membership of each linguistic variable.

Using parameters values from Table 3 we get $\alpha=0.028$ and $\beta=7.068$ and the following matrices

$$
\begin{aligned}
A_{s} & =\left(\begin{array}{cccc}
0.995 & 0.005 & 0.0028 & 0 \\
0.005 & 0.395 & 0 & 0 \\
0 & 0 & 1 & 0 \\
0 & 0 & 0 & 1
\end{array}\right), \quad B_{s}=\left(\begin{array}{cccc}
0 & 0 & 0 & 0 \\
0 & 0 & 0 & 0 \\
0.1 & 0 & 0 & 0 \\
0 & 0.1 & 0 & 0
\end{array}\right), \quad s=1,2,3, \\
C_{1} & =\left(\begin{array}{c}
0 \\
0.3231 \\
0 \\
0
\end{array}\right), \quad C_{2}=\left(\begin{array}{c}
0 \\
0.1951 \\
0 \\
0
\end{array}\right), \quad C_{3}=\left(\begin{array}{c}
0 \\
0.1747 \\
0 \\
0
\end{array}\right) .
\end{aligned}
$$

Table 1. Variables and their operating points.

\begin{tabular}{cc}
\hline Variable & Operating Points \\
\hline $\left.\mathrm{CO}_{2}\right]_{\mathrm{t}}$ & {$[25][30][35]$} \\
{$\left[\mathrm{CO}_{2}\right]_{\mathrm{v}}$} & {$[15][22.5][30]$} \\
$H$ & {$[50][115][180]$} \\
$\dot{V}_{A}$ & {$[4][14.5][25]$} \\
\hline
\end{tabular}

Table 2. Variables and their corresponding degrees of membership.

\begin{tabular}{cccc}
\hline Variable & $W_{1 f}$ & $W_{2 f}$ & $W_{3 f}$ \\
\hline$\left[\mathrm{CO}_{2}\right]_{\mathrm{t}}$ & 0 & 0.4 & 0.6 \\
{$\left[\mathrm{CO}_{2}\right]_{\mathrm{v}}$} & 0 & 0.27 & 0.73 \\
$H$ & 0.3 & 0.7 & 0 \\
$\dot{V}_{A}$ & 0.38 & 0.62 & 0 \\
\hline
\end{tabular}

Table 3. Value of used parameters.

\begin{tabular}{cccc}
\hline Parameter & Value & Parameter & Value \\
\hline$\dot{Q}$ & 6 & $P^{f} a \mathrm{CO}_{2}$ & 38 \\
$K_{v}$ & 0.05 & $P^{f} a \mathrm{O}_{2}$ & 95 \\
$\mathrm{pH}$ & 7.35 & $\left(\mathrm{CO}_{2}\right)_{t}^{e}$ & 26.5 \\
$\mathrm{SaO}_{2}$ & 0.98 & $\left(\mathrm{CO}_{2}\right)_{V}^{e}$ & 18.5 \\
$\mathrm{CO}_{2}$ & 0.21 & $P_{\mathrm{H}_{2} \mathrm{O}_{2}}$ & 47 \\
$P_{\mathrm{ATM}}$ & 760 & $R Q$ & 0.8 \\
$F_{I \mathrm{IO}_{2}}$ & 0.21 & $S V$ & 0.7 \\
$q_{\mathrm{CO}_{2}}$ & 10 & $K_{\mathrm{CO}_{2}}$ & 0.0065 \\
$q_{\mathrm{O}_{2}}$ & 15 & $K_{\mathrm{CO}_{2}}$ & 0.244 \\
$q_{H}$ & 100 & {$\left[\mathrm{O}_{2}\right]_{a}$} & 0.197 \\
$q_{V}$ & 100 & {$\left[\mathrm{O}_{2}\right]_{v}$} & 0.147 \\
$K$ & 863 & & \\
\hline
\end{tabular}




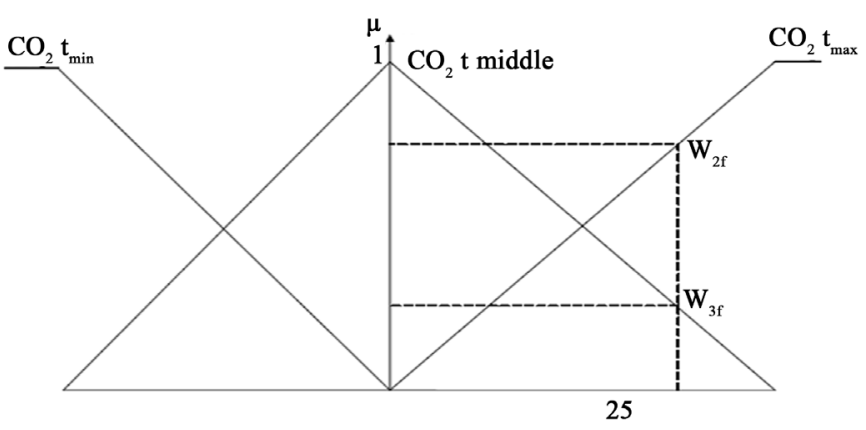

(a)

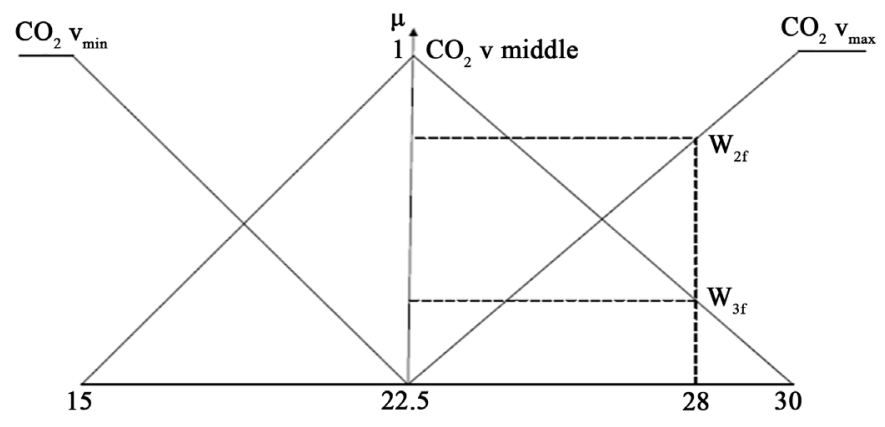

(b)

Figure 2. Membership function of $\left[\mathrm{CO}_{2}\right]_{t}$ (a) and $\left[\mathrm{CO}_{2}\right]_{v}$ (b).

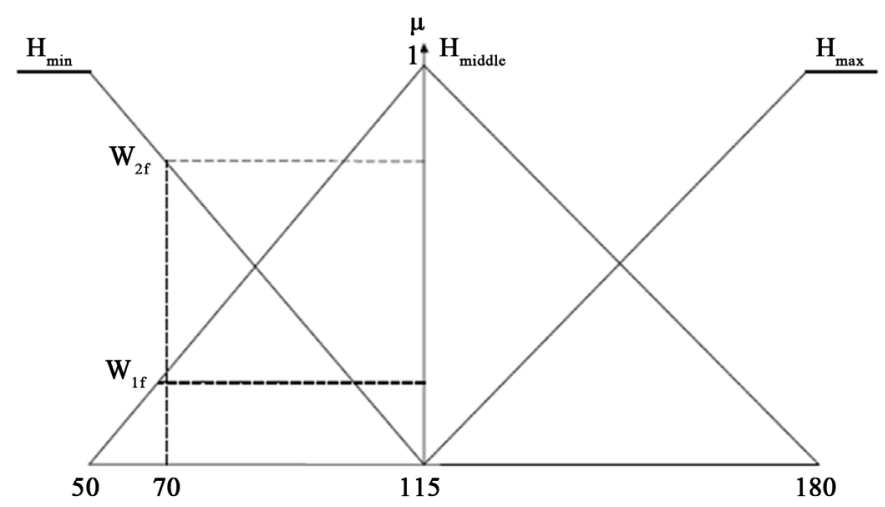

(a)

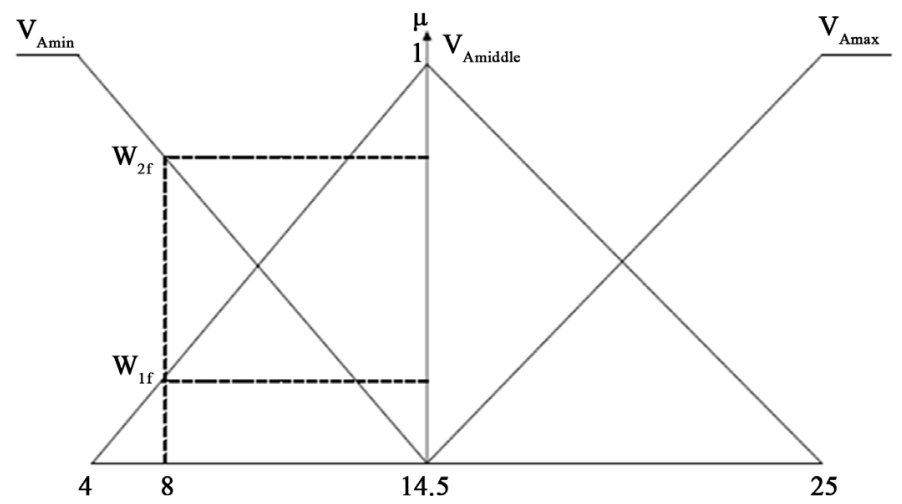

(b)

Figure 3. Membership function of $H$ (a) and $\dot{V}_{A}$ (b). 
The next step of the fuzzy logic strategy at this point is the defuzzification. The formulas used in the defuzzification are illustrated in (26). Now considering our Equation (29), the matrices $A_{s}$ and $B_{s}$ remain unchanged. However, as matrices $C_{1}, C_{2}$ and $C_{3}$ contain a variable $\dot{V}_{A}$, calculation is made after replacing $\dot{V}_{A}$ with its operating points presented in Table 1 . With parameters from Table 3, we get

$$
A=\left(\begin{array}{cccc}
0.995 & 0.005 & 0.0028 & 0 \\
0.005 & 0.395 & 0 & 0 \\
0 & 0 & 1 & 0 \\
0 & 0 & 0 & 1
\end{array}\right), \quad B=\left(\begin{array}{cccc}
0 & 0 & 0 & 0 \\
0 & 0 & 0 & 0 \\
0.1 & 0 & 0 & 0 \\
0 & 0.1 & 0 & 0
\end{array}\right), \quad \text { and } \quad C=\left(\begin{array}{c}
0 \\
0.2437 \\
0 \\
0
\end{array}\right)
$$

Since there are three linear state systems, the solution leads to three feedback controls of the form

$$
U_{k}=-K_{i, S} X_{k}, \quad s=1,2,3,
$$

where $K_{i}$ is a gain feedback. The implementation can be made in several platforms. Here we use MATLAB package where we use the built-in function dare for solving discrete Riccati Equation (23) if $Q=B \quad A_{t}=A_{s}$ $B_{t}=B_{s}$. After calculation, we obtain

$$
K=\left(\begin{array}{cccc}
0.0104 & 0.0013 & 3.3354 & 0 \\
0 & 0 & 0 & 2.2468 \\
0.1880 & 0.0125 & 0.0110 & 0 \\
0.0296 & 0.0401 & 0.0031 & 0
\end{array}\right)
$$

For solving the optimal control problem (7) subject to the system (1)-(2) and (3)-(4), we take $\mathrm{P}^{f} \mathrm{aCO}=38 \mathrm{mmHg}$ and $\mathrm{P}^{f} \mathrm{aO}_{2}=95 \mathrm{mmHg}$. The numerical simulation gives the graphical results. The Figure 4 illustrates both the variation of the heart rate and ventilation rate. Figure 5 presents the impact of physical activity due to two controls of cardiovascular-respiratory system in the variation of tissue and vascular carbon dioxide while Figure 6 shows the responses of the partial pressure of carbon dioxide and oxygen.

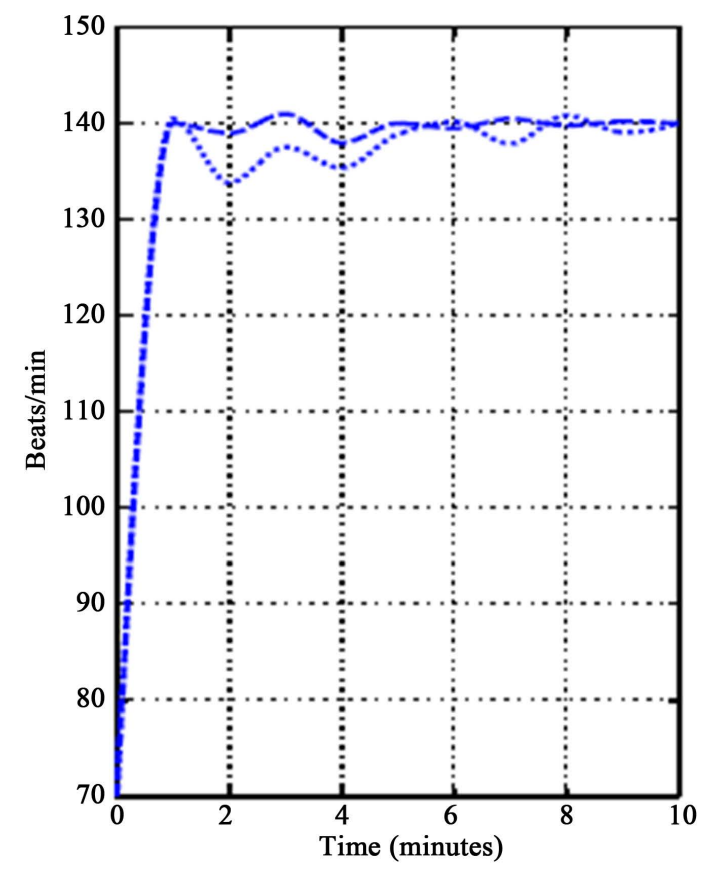

(a)

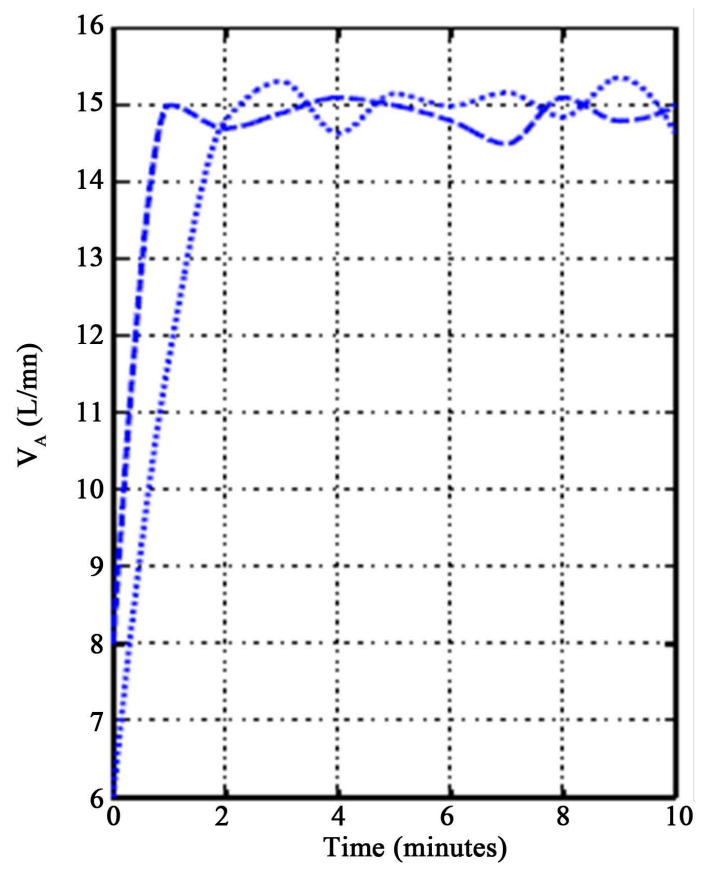

(b)

Figure 4. Variation of heart rate (a) and Ventilation rate (b) for a 30 years old woman during jogging as her physical activity. The curves in dotted line represent the parameter for the direct approach. The curve dashed line show the parameter for the approach integrating the fuzzy logic strategy. 


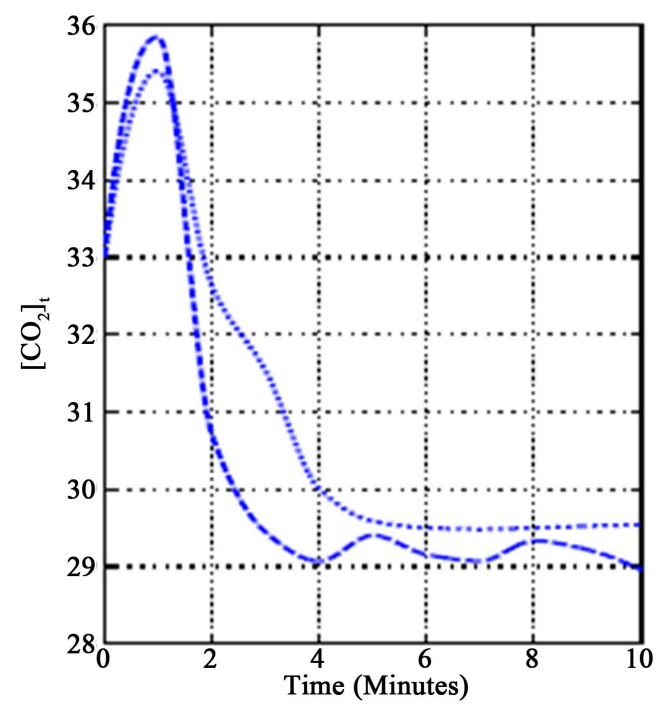

(a)

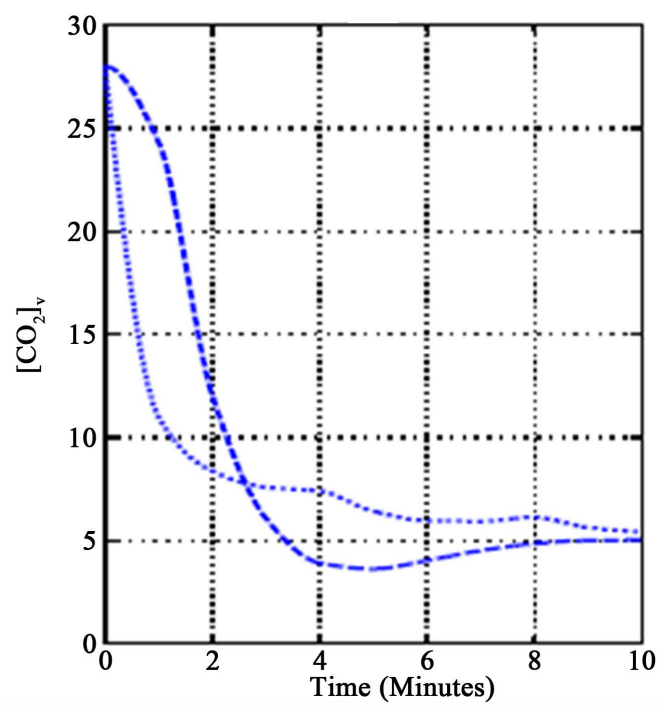

(b)

Figure 5. Variation of carbon dioxide in tissue (a) and in vascular (b) for a 30 years old woman during jogging as her physical activity. The curves in dotted line represent the parameter for the the direct approach. The curve dashed line show the parameter for the approach integrating the fuzzy logic strategy.

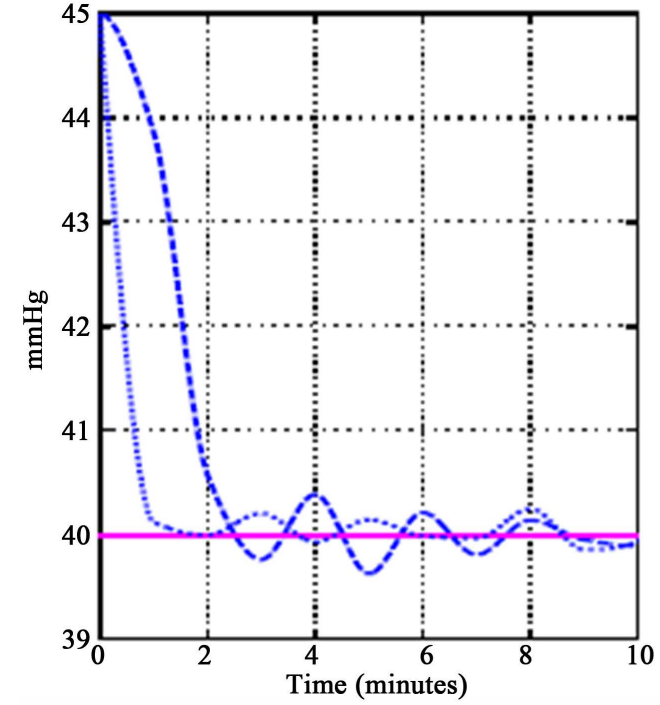

(a)

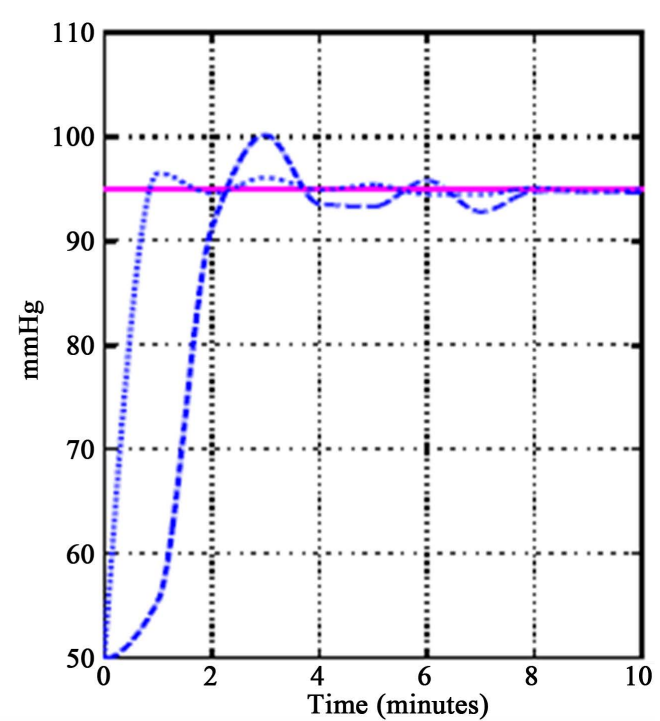

(b)

Figure 6. Variation of optimal arterial partial pressure of carbon dioxide (a) and oxygen (b) for a 30 years old woman during jogging as her physical activity. The curve in solid line represents the wanted value. The curve in dotted line indicates the optimal parameter for the approach integrating the fuzzy logic strategy. The curve in dashed line represents the optimal parameter for the direct approach.

The controls variation of the cardiovascular respiratory system are represented in Figure 4 which shows the increase of both the heart rate and the alveolar ventilation until they reach a stabilized state. It is a perfect representation of the importance of physical activity in the regulation of the cardiovascular respiratory system; in order to avoid or even heal non severe Hypoxemic-Hypoxia. In the case of Hypoxemic-Hypoxia, there is a perfect deficit of oxygen in the body. The ventilation rate plays an important role in the gas supply and regulation through the body. An increase in heart rate and ventilation rate results in an adequate and regular supply of both oxygen and carbon dioxide in the body. The Figure 5 shows a decrease of tissue and venous carbon dioxide concentration. This results from the brut increase of ventilation during the initial stage of the physical activity 
which is followed by a gradual increase of ventilation. The absence of a perfect ventilation leads to an increase (decrease) of carbon dioxide $\left(\mathrm{PaCO}_{2}\right)$ and oxygen $\left(\mathrm{PaO}_{2}\right)$ resulting from an accumulation of lactic acid. For a 30 years old woman during jogging as her physical activity, the Figure 6 shows the arterial partial pressure of carbon dioxide (resp. oxygen) decreases (resp. increases) in the time of physical activity until the stabilization at normal value. The results obtained in this work are rather satisfactory. In particular, the reaction of the cardiovascular and respiratory system to physical activity can be modeled and a feedback can be approximated by the solution of a linear quadratic problem. Physical activity reduces the risk of Hypoxemic-Hypoxia or contacting any cardiovascular-respiratory disease. Physical activity induces important changes in the stabilization of cardiac, vascular and blood

\section{Concluding Remarks}

In this work, two numerical approaches have been compared to determine the optimal trajectories of arterial pressures of of carbon dioxide and oxygen as response to controls of cardiovascular-respiratory system subjected to a physical activity. The finding results show that those two used methods are satisfactory and closed. Consequently, the approach integrating the fuzzy logic strategy is very important for the resolution of the optimal control problem. In particular, it gives the optimal trajectories of cardiovascular-respiratory system in the same way it ensures their performance.

\section{References}

[1] Cymerman, A. and Rock, P.B. (2009) Medical Problems in High Mountain Environments. A Handbook for Medical of Ficers. USARIEM-TN94-2. US Army Research Institute of Environmental Medicine Thermal and Mountain Medicine Division Technical Report.

[2] Gutierrez, G. (2004) A Mathematical Model of Tissue-Blood Carbon Dioxide Exchange during Hypoxia. American Journal of Respiratory and Critical Care Medicine, 169, 525-533.

[3] Timischl, S., Batzel, J. J. and Kappel, F. (2000) Modeling the Human Cardiovascular-Respiratory Control System: An Optimal Control Application to the Transition to Non-REM Sleep. Spezialforschungsbereich F-003 Technical Report 190, Karl-Franzens-Universitat, Graz.

[4] Severinghaus, J.W. (1979) Simple, Accurate Equations for Human Blood $\mathrm{O}_{2}$ Dissociation Computations. Journal of Applied Physiology, 46, 599-602.

[5] Giovannini, I., Chiarla, C., Boldrini, G. and Castagneto, M. (1993) Calculation of Venoarterial $\mathrm{CO}_{2}$ Concentration Difference. Journal of Applied Physiology, 74, 959-964.

[6] Douglas, A.R., Jones, N.L. and Reed, J.W. (1988) Calculation of Whole Blood $\mathrm{CO}_{2}$ Content. Journal of Applied Physiology, 65, 473-477.

[7] Yakowitz, S.J. (1986) The Stagewise Kuhn-Tucker Condition and Differential Dynamic Programming. IEEE Transactions on Automatic Control, 31, 25-30.

[8] Masmoudi, N.K. and Derbel, N. (2003) Optimal Control of Nonlinear Systems by Fuzzy Logic. ISCIII, Nabeul,.

[9] Sugeno, M. and Murakami, K. (1984) Fuzzy Parking Control of Model Car. 23rd IEEE Conferences on Decision and Control, Las Vegas, 12-14 December 1984, 902-903. http://dx.doi.org/10.1109/CDC.1984.272144

[10] Takagi, T. and Sugeno, M. (1985) Fuzzy Identification of Systems and Its Applications to Modeling and Control. IEEE Transactions on Systems Man and Cybernetics, 15, 116-132. http://dx.doi.org/10.1109/TSMC.1985.6313399

[11] Park, M.I., Kim, E., Ji, S. and Park, M. (1987) A New Approach to Fuzzy Modeling. IEEE Transactions on Fuzzy Systems, 5, 328-337.

[12] Jacobson, D., Lele, D. and Speyer, J.L. (1971) New Necessary Conditions of Optimality for Control Problems with State-Variable Inequality Constraints. Journal of Mathematical Analysis and Applications, 35, 255-284. http://dx.doi.org/10.1016/0022-247X(71)90219-8

[13] Kwakernaak, H. and Savan, R. (1972) Linear Optimal Control Systems. Wiley, Inter-Science, New York.

[14] Trélat, E. (2005) Contrôle Optimal: Théeorie et Applications, Vuibert, Collection, Mathématiques Concrètes.

[15] Ntaganda, J.M. and Mampassi, B. (2007) Modelling Blood Partial Pressures of the Human Cardiovascular Respiratory System. Applied Mathematics and Computation, 187, 1100-1108. http://dx.doi.org/10.1016/j.amc.2006.09.016 
Scientific Research Publishing (SCIRP) is one of the largest Open Access journal publishers. It is currently publishing more than 200 open access, online, peer-reviewed journals covering a wide range of academic disciplines. SCIRP serves the worldwide academic communities and contributes to the progress and application of science with its publication.

Other selected journals from SCIRP are listed as below. Submit your manuscript to us via either submit@scirp.org or Online Submission Portal.
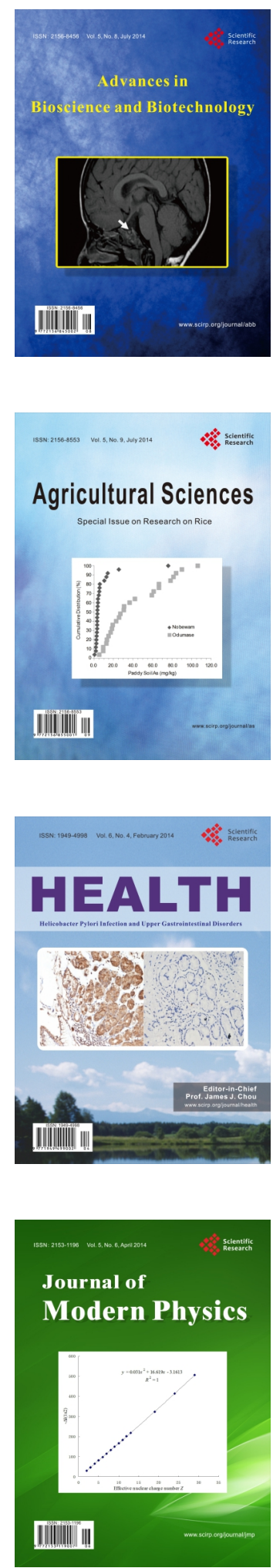
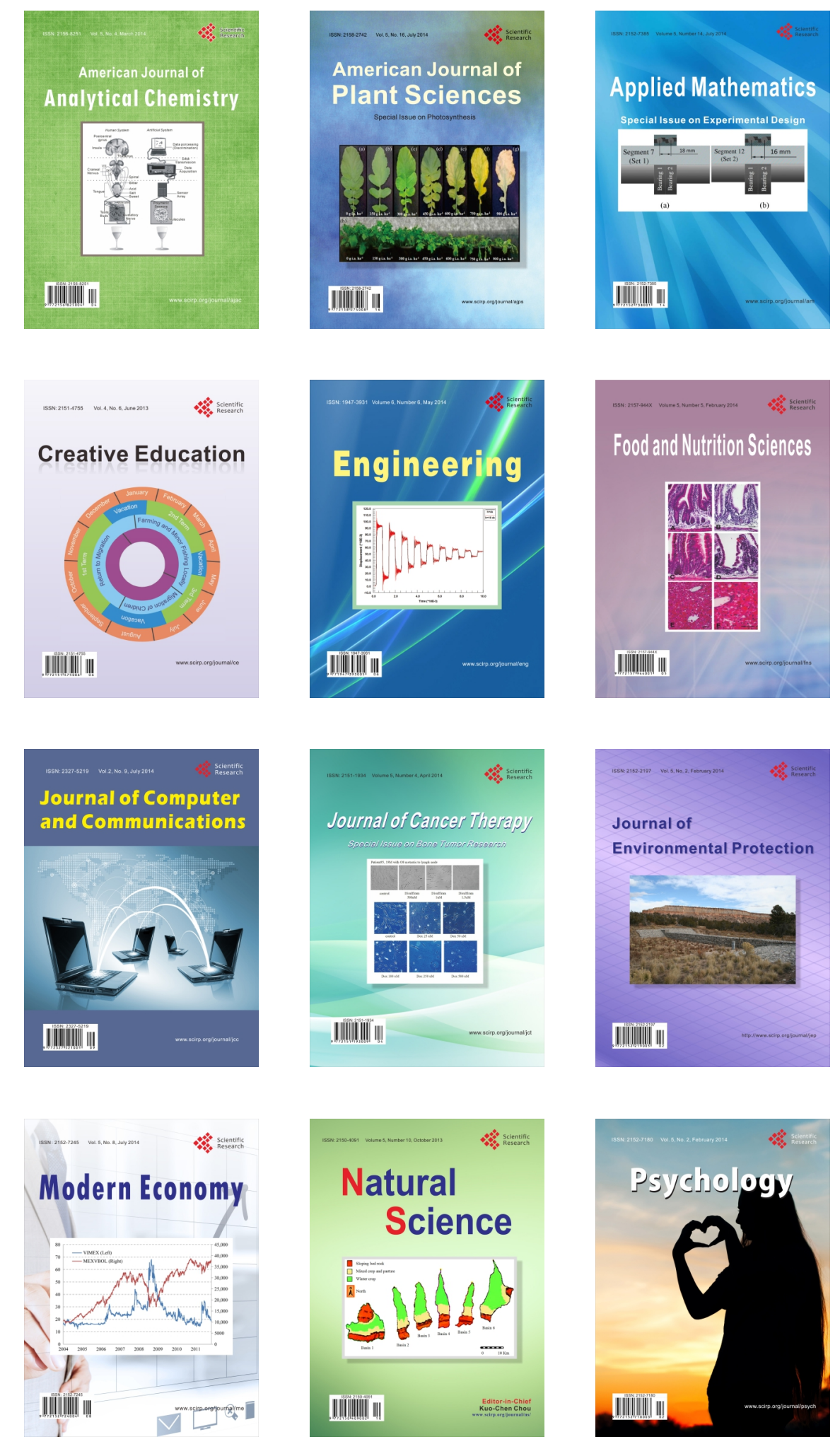